\title{
Comparative Proteome Analysis of the Penultimate Internodes of Barley Genotypes Differing in Stem Reserve Remobilization Under Drought Stress
}

\section{Zohreh Hajibarat}

Department of Plant Sciences and Biotechnology, Faculty of Life Sciences and Biotechnology, Shahid Beheshti University, Tehran, Iran

Abbas Saidi

Department of Plant Sciences and Biotechnology, Faculty of Life Sciences and Biotechnology, Shahid Beheshti University, Tehran, Iran

Maryam Shahbazi

Gorgan University of Agricultural Sciences and Natural Resources, Gorgan, Iran

Mehrshad Zeinalabedini

Department of Systems and Synthetic Biology, Agricultural Biotechnology Research Institute of Iran, (ABRII), Agricultural Research, Education and Extension Organization (AREEO), Karaj, Iran

Ahmad Mosuapour Gorji

Department of Vegetable Research, Seed and Plant Improvement Institute (SPII), Agricultural Research, Education and Extension Organization (AREEO),

Karaj, Iran

Mehdi Mirzaei

Australian Proteome Analysis Facility, Macquarie University, Sydney, NSW

Ghasem Hosseini Salekdeh

Department of Molecular Sciences, Macquarie University, North Ryde, NSW

Mohammad Reza Ghaffari ( $\nabla$ mrghaffari52@gmail.com )

Department of Systems and Synthetic Biology, Agricultural Biotechnology Research Institute of Iran, (ABRII), Agricultural Research, Education and Extension Organization (AREEO), Karaj, Iran

\section{Research Article}

Keywords: barley, remobilization, drought stress, penultimate internodes

Posted Date: January 11th, 2022

DOI: https://doi.org/10.21203/rs.3.rs-1178453/v1

License: () (1) This work is licensed under a Creative Commons Attribution 4.0 International License. Read Full License 


\section{Abstract}

Barley yield relies more on stem reserves under stress conditions at the grain filling stage. At terminal drought stresses, the remobilization of reserved assimilates from stem to seed contributes a major role in yield. To understand the molecular mechanism of stem reserve utilization during drought stress, a comparative proteome and physiological analyses were performed on the penultimate internodes of three genotypes of barley Yousef (tolerant), Morocco (susceptible), and PBYT17 (semi-tolerant) under drought stress at 21 and 28 days after anthesis (DAA). Under water stress and well-watered conditions Yousef showed significantly higher RWC, grain yield, and stem reserve remobilization capacity than susceptible and semi-tolerant genotypes. The proteome analysis led to the identification of 1580 differentially abundant proteins (DAPs), of which 759 and 821 proteins were differentially expressed at 21 and 28 DAA, respectively. Tolerant genotype in response to drought stress increased the abundance of several plant cell wall polysaccharide degradation proteins and protein kinases associated with posttranslational-associated, which might accelerate remobilization process for seed biomass formation compared to susceptible one under drought stress. However, the susceptible genotype increased the abundance of proteins involved in RNA metabolism and transcriptional changes to save energy sources for the growth and survival during drought stress. These findings suggest that barley might response to water stress by efficiently remobilize assimilates from stem to grain through specific remobilization processes.

\section{Introduction}

Water scarcity severely decreases crop productivity worldwide ${ }^{1}$. Iran is located in an arid and semi-arid region, where terminal drought stress is pervasive and substantial ${ }^{2}$. It is typical to have elevated soil evaporation in spring, particularly when cereal crops enter the seed filling stage ${ }^{3}$. Barley (Hordeum vulgare L.) is the fourth most important crop worldwide, ${ }^{4}$ and its grain yield is significantly influenced by terminal drought stress ${ }^{5}$. Drought stress may decrease spikes per unit area, grain per spike, or seed weight ${ }^{6}$. Under drought stress, cereals remobilize $10-45 \%$ more dry matter reserved in the vegetative tissues to the grains compared to well-watered conditions ${ }^{7,8,9}$. Furthermore, the lower internodes contribute the maximum dry matter (55\%) as compared with the penultimate internode $(27 \%)$ and the peduncle $(18 \%)^{3}$. The remobilization efficiency of dry matter, which is the ratio of mobilized dry matter to maximum weight penultimate, is more considerable in the upper internodes, particularly in penultimate compared to peduncle and lower intermediate under both well-watered and water stress conditions ${ }^{3,9,10}$. Water-soluble carbohydrates (WSCs) can accumulate in the stems of cereals. Various studies have shown that carbohydrate storage compound increases after anthesis to maintain grain filling rate, especially when photosynthesis is severely disrupted under water stress ${ }^{7,15}$. Droughttolerant genotypes usually accumulate more carbohydrate storage sources in the stem than susceptible genotypes. Proteomics can be used as a practical approach to develop drought-tolerant cultivars by identifying the proteins involved in stem reserve remobilization. This technique makes it possible to develop molecular markers related to stem reserved remobilization traits to breed barley cultivars in response to terminal drought stress ${ }^{17}$. The previous study showed the remobilization of stem reserves assimilates to developing seeds is mediated by proteins involved in photosynthesis, senescence, and signalling proteins in rice and wheat contrasting genotypes under drought stress ${ }^{18,19}$. Further study showed that the remobilization of nitrogen and carbohydrate degraded enzymes in stem reserve remobilization ${ }^{20}$. Thus, one of the strategies considered in tolerant cultivars with growth-limiting environmental stresses such as drought is to increase assimilates in stem during the grain filling process by increasing the stem reserves during growth and prolonging the remobilization period ${ }^{7,12}$. It is well documented that water-soluble carbohydrate levels are higher in penultimate at grain filling stages ${ }^{11}$. In addition, a positive and significant correlation was observed between the rate of penultimate remobilization and grain yield in various barley plants ${ }^{12}$. Likewise, the genotypic variation observed in different crops indicates that breeding for the increased contribution of stem reserves to grain yield could be possible in cereals to stabilize grain yield in stress conditions. Thus, WSCs can be considered biochemical markers for selecting stress-tolerant genotypes ${ }^{16}$. To identify the key proteins involved in barley stem reserve remobilization, we examined three barley contrasting genotypes for accumulation and remobilization characteristics under water stress conditions. In this report, we show differences in remobilization characteristics in three barley contrasting genotypes. Consistent with these results, our shotgun proteomics further indicates an interplay between proteins involved in signalling, transcriptional and posttranscriptional regulations, and transports for stem reserves remobilization. The general roles of metabolic pathways for maintaining barley under water stress were further described.

\section{Methods}

\section{Plant materials and terminal drought stress condition}

Seeds of spring barley Yousef cultivar and preliminary barley yield trial line PBYT17 were obtained from Seed and Plant Improvement Institute (SPII, Karaj, Iran). The Seeds of Morocco cultivar were also donated by Dr. Adnan Al-Yassin from the International Center for Agricultural Research in the Dry Area (ICARDA). Yousef is a drought-tolerant genotype that is cultivated in temperate arid regions of Iran ${ }^{59}$. However, Morocco (drought-susceptible genotype) and PBYT17 (semi-drought tolerant genotype) were examined for comparative analysis of traits 60,61 .

The plant material was formally identified by corresponding authors Mohammad Reza Ghaffari and Abbas Saidi and confirmed by Dr. Habibollah Ghazvini, in Cereal Research Department (CRD), at Seed and Plant Research Institute (SPII), where the collected material has been deposited. Furthermore, our research complied with local guidelines and legislation, and the required permissions and licenses for the study were obtained.

\section{Terminal drought stress treatment}

Seeds of three genotypes of barley were grown in two well-drained plots $(9 \mathrm{~cm} \times 1.7 \mathrm{~m})$ containing loamy soil, spacing of $10 \mathrm{~cm}$ between rows and $5 \mathrm{~cm}$ between plants in a row under greenhouse conditions. The experiment was performed as a factorial based on a randomized complete block design with two treatments (control, drought stress) and three replications. The genotypes were planted in 9 rows providing 360 plants for each treatment. Drip irrigation was implemented, and plants were grown under well-watered conditions (at soil field capacity, FC) until anthesis when the drought stress was imposed by withholding water until 40\% FC soil water content (equal to $-1.5 \mathrm{MPa}$ soil water potential) on the $28^{\text {th }}$ day after anthesis (DAA). The soil moisture for the well- 
watered and drought-stressed plots was measured by digital moisture and by weighing the pots, followed by maintaining the soil water content at the desired level by adding the evaporated water. The penultimate internodes from the main stem were sampled for proteome analysis at 21 and 28 DAA, rapidly frozen in liquid nitrogen, and stored at $-80^{\circ} \mathrm{C}$ for protein extraction. The grain yield was determined by weighing 15 spikes detached from the plants after incubating at $70^{\circ} \mathrm{C}$ for 72 hours.

\section{Relative water content (RWC) measurement}

The leaf RWC was calculated as described previously ${ }^{62}$. Briefly, three biological replicates of the flag leave samples were harvested 28 DAA after the initiation of water limitation. The leaf samples were weighed to determine the fresh weight (FW). The samples were immersed in $50 \mathrm{~mL}$ Falcon tubes containing distilled water, incubated under dark conditions at $4{ }^{\circ} \mathrm{C}$ overnight, blotted dry, and weighed to determine the turgid weight (TW). The leaf samples were then oven-dried at $60^{\circ} \mathrm{C}$ for $24 \mathrm{~h}$ to obtain the dry weight (DW). The RWC was calculated in percentage using the formula RWC $=(F W-D W) /(T W-D W)^{\star} 100$.

\section{Characterization of Stem remobilization}

Remobilization characteristics were measured randomly from the main stems with the same height at 7, $14,21,28$ and 100 DAA. Samples were dried at $80^{\circ} \mathrm{C}$ for 48 hours to minimize respiration and weight loss. Then, the leaf blade and sheaths were detached from the stem, and the length and dry weight of internodes (peduncle, penultimate, and lower internodes) were determined. Dry weight changes were measured to calculate the stem reserve and remobilization level. The specific weight of each internode was obtained by dividing weight by the length of internodes. The remobilization rate was also calculated by differing the maximum internode weight $\left(\mathrm{W}_{\max }\right)$ among $7,14,21$, and 28 DAA and the internode weight at the physiological maturity stage $\left(\mathrm{W}_{\text {mat }}\right)$. The remobilization efficiency of each internode was estimated as $\left(\mathrm{W}_{\mathrm{max}}-\mathrm{W}_{\text {mat }} / \mathrm{W}_{\mathrm{max}}\right) \times 100$ as described previously ${ }^{3}$.

\section{Protein extraction and shotgun proteomics}

Protein was extracted from the freeze-dried (100-mg sample), powdered penultimate in $1.5 \mathrm{~mL}$ acetone containing trichloroacetic acid (10\% v/v) and $\beta$ mercaptoethanol $(0.07 \% \mathrm{v} / \mathrm{v})^{63}$. Then, the mixture was centrifuged at $16,000 \mathrm{~g}$ for $\left.30 \mathrm{~min}\right)$, and the resulting pellet was rinsed twice in $1.5 \mathrm{~mL}$ acetone, followed by a re-centrifugation at $16,000 \mathrm{~g}$ for $30 \mathrm{~min}$. Vacuum centrifugation was used to lyophilize the pellet followed by re-suspension of the pellet in 400 $\mu \mathrm{L} 50 \mathrm{mM}$ Tris- $\mathrm{HCl}(\mathrm{pH} 8.8)$ containing $2 \% \mathrm{w} / \mathrm{v}$ SDS. This solution was then extracted by methanol-chloroform as previously described ${ }^{64}$. The final pellet was dried at room temperature (RT) and dissolved in $80 \mu \mathrm{L} 8 \mathrm{M}$ urea, $100 \mathrm{mM}$ Tris- $\mathrm{HCl}$ (pH 8.8). A 2D-Protein Quant Kit (BioRad, Hercules, USA) was used to assay the protein concentration, followed by subjecting the samples to SDS-PAGE ( $80 \mu \mathrm{g}$ sample per well of a Bio-Rad $10 \%$ Tris-HCl precast gel, run at $150 \mathrm{~V}$ for $1 \mathrm{~h}$ ) The proteins were visualized by staining in colloidal Coomassie Blue as described ${ }^{65}$. Each lane was sliced into 16 equal length pieces, de-stained by immersion in $100 \mathrm{mM} \mathrm{NH} 4 \mathrm{HCO}, 50 \% \mathrm{v} / \mathrm{v}$ acetonitrile, $100 \mathrm{mM} \mathrm{NH} 4 \mathrm{HCO} 3$ and dehydrated by immersion in $100 \%$ acetonitrile. The proteins within the gel pieces were reduced by treating with $50 \mu \mathrm{L} 10 \mathrm{mM} \mathrm{DTT}, 50 \mathrm{mM} \mathrm{NH} 4 \mathrm{HCO} 3$ at $37^{\circ} \mathrm{C}$ for $1 \mathrm{~h}$, and then alkylated by adding $50 \mu \mathrm{L} 50 \mathrm{mM}$ iodoacetamide dissolved in $50 \mathrm{mM} \mathrm{NH} 4 \mathrm{HCO} 3$ at RT in dark for $1 \mathrm{~h}$. Further, the gel pieces were briefly rinsed in $100 \mathrm{mM} \mathrm{NH} 4 \mathrm{HCO}, 200 \mu \mathrm{L} 50 \%$ acetonitrile, $100 \mathrm{mM}$ $\mathrm{NH} 4 \mathrm{HCO} 3$ for $10 \mathrm{~min}$, dehydrated by flooding with $100 \%$ acetonitrile, and air-dried. The proteins were digested overnight at $37^{\circ} \mathrm{C}$ in $20 \mu \mathrm{L} 12.5 \mathrm{ng} / \mu \mathrm{L}$ trypsin in $50 \mathrm{mM} \mathrm{NH} 4 \mathrm{HCO} 3$. Peptides were extracted from the gel pieces by adding $30 \mu \mathrm{L} 50 \% \mathrm{v} / \mathrm{v}$ formic acid and $2 \% \mathrm{v} / \mathrm{v}$ acetonitrile. For further analysis, the supernatant was dried down by vacuum.

\section{LC-MS/MS analysis}

Each sample was subjected to a nano LC-MS/MS device attached to an LTQ-XL ion trap mass spectrometer (Thermo Fisher, CA, USA). The $200 \AA \AA$, $5 \mu$ M analytical columns utilized contained Magic C18AQ resin (Michrom Bioresources, CA, USA) packed into a fused silica capillary with an integrated electrospray tip. Reverse-phase chromatography was performed, the initial wash solution buffer $A$ ( $5 \% \mathrm{v} / \mathrm{v}$ acetonitrile, $0.1 \mathrm{v} / \mathrm{v}$ formic acid) was passed through the column for $10 \mathrm{~min}$ at $1 \mu \mathrm{L}$ min-1. The samples containing $1 \mu \mathrm{l}$ of extracted peptides were loaded and separated by passing through a gradient of $0-50 \%$ Buffer $B$ ( $95 \%$

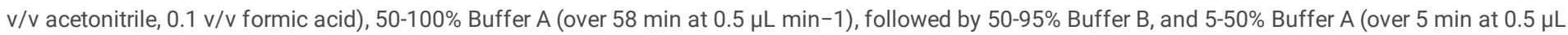
min-1). Mass-spectrometric data were acquired over the range of 400-1500 amu. Peak recognition and dynamic exclusion window, set to $90 \mathrm{~s}$ and MS/MS of the top six most intense precursor ions at 35\% normalization collision energy, were performed using Xcalibur software v2.06 (Thermo Fisher, CA, USA) as described by ${ }^{66}$. For each experiment, the 16 fractions were processed sequentially and a merged, non-redundant output file was generated for protein identification using the Uniprot Hordeum vulgare protein database (www.uniprot.org) search and PlantPres database (3466 entries, version 2017 ) ${ }^{67}$. In order to compensate for null values and to enable log transformation for the subsequent statistical analysis, protein abundance data were calculated using normalized spectral abundance factors (NSAF) with an addition of a spectral fraction of 0.5 to all spectral counts. Summed NSAF values were used as a measure of relative protein abundance.

\section{Bioinformatics analysis of proteomic data and statistical tests}

Statistical differences of the mean values for the physiological traits was tested using the analysis of variance (ANOVA) using SAS software (SAS Inc., USA). Likewise, Duncan's multiple comparison post-hoc test was done in SAS software. For the differentially abundant proteins (DAPS), a pairwise comparison was performed using student t-tests of the NSAF data. Proteins with a p-value less than 0.05 were measured as differentially expressed. Fold changes were estimated as a ratio of the NSAF value of proteins under drought stress to normal conditions. The unique and common DAPs were drawn using Upset database (https://gehlenborglab.shinyapps.io/upsetr/).

\section{Functional annotation and gene ontology analysis of the DAPs}


The nucleotide sequences of DAPs were uploaded to the online annotation tool of Mapman (http://www.plabipd.de/portal/mercator-sequence-annotation) for functional annotation and categorization using default parameters ${ }^{68}$. For multivariate statistical analysis, PLS-DA (partial least squares discriminant analysis) was utilized using MetaboAnalyst software ${ }^{69}$. Van Diagram was used to show unique and common proteins between three genotypes using the (https://intervene.shinyapps.io/intervene/) database in 21 and 28 DAA.

\section{Results}

\section{Physiological responses of barley to drought stress}

Figure 1 illustrates the relative water content (RWC) and grain yield among Yousef, Morocco, and PBYT17 in well-watered and drought-stress plants. A decline in RWC was observed for Morocco, PBYT17, and Yousef by $17 \%, 20 \%$, and $10 \%$ in drought-stressed plants, respectively $(P<0.01)$ (Fig.1a) as compared with well-watered one. Under drought stress conditions, grain yield was reduced by $48 \%$ and $45 \%$ in Morocco and PBYT17, respectively (Fig. $1 \mathrm{~b}$ ). However, Yousef had no significant grain yield reduction under drought stress conditions.

\section{Remobilization characteristics changes under drought stress}

Yousef experienced a significant increase in the maximum specific weight $\left(\mathrm{mg} \mathrm{cm}^{-1}\right)$ of peduncle and penultimate under drought stress conditions. By contrast, this trait had no significant change between well-watered and drought-stressed plants of Morocco and PBYT17 (Table 1). Furthermore, the remobilization rate $\left(\mathrm{mg} \mathrm{plant}^{-1}\right)$ in peduncle and penultimate internodes was significantly increased in Yousef and PYBT17 under drought stress condition (Table 1). The mobilization efficiency in the peduncle, penultimate and lower internodes increased significantly in Yousef under drought stress conditions. Meanwhile, it had no significant change in Morocco and PYBT17 (Table 1).

\section{Changes in remobilization characteristics changes after anthesis}

Figure 2a compares the specific weight of penultimate internodes over 100 days after flowering. Overall, the three genotypes experienced different trends in the time period. The specific weight of penultimate internodes in Yousef considerably and non-significantly increased in well-watered and drought-stressed plants at 7 DAA. Afterward, although a change in the specific weight of penultimate internodes was seen for the next three weeks in well-watered and water stressed plants. However, the plants experienced a significant difference at 21 DAA. Then the graph peaked at 28 DAA and then fell over time (Fig. 2a). Regarding Morocco cultivar's specific weight of penultimate internodes in well-watered and drought-stressed plants, they showed a non-significant increase for three weeks and peaked at 21 DAA (Fig. 2b). Then the specific weight of penultimate internodes fell over time. By contrast, the specific weight of penultimate internodes in PBYT17 increased non-significantly for seven days in well-watered and drought stressed plants. Afterward, they fell over and experienced a fluctuation for four weeks and significantly changed at 21 DAA (Fig. 2c).

\section{Pairwise differential abundance analysis of proteins}

To explore proteins associated with drought response in genotypes differing drought tolerant and remobilization characteristics, a pairwise comparison analysis was performed. Overall, 309 protein increased and 450 proteins decreased in abundance in all the three genotypes at 21 DAA (Fig $3 a$ and b). Both PBYT17 and Morocco showed the highest uniquely differentially regulated proteins, whereas the lowest regulated proteins was observed in Yousef. In Yousef, 14.2 percent of the detected proteins were involved in carbohydrate metabolism, 5 percent in lipid metabolism, 8 percent in amino acids metabolism, 2 percent in each of secondary metabolism and cell wall degradation, 14.2 percent in each of stress and proteins metabolism (synthesis and degradation), and 5 percent each in transport, misc, RNA, and DNA. In Morocco, detected DAPs were implicated in carbohydrate metabolism (6\%), protein metabolism (40.46\%), amino acid metabolism (8\%), redox (4\%), misc (8\%), signalling (10\%), nucleotide metabolism (4), RNA (6\%) and DNA (6\%). In PBYT17, the largest percentage of detected proteins was involved in carbohydrate metabolism (7.5\%), mitochondrial electron transport / ATP synthesis (28\%), lipid metabolism (2.8\%), amino acids metabolism (3.7\%), hormone metabolism (4.7\%), stress (4.7\%), mitochondrial 2-oxoglutarate/malate carrier protein (misc) (8.4\%), proteins metabolism (synthesis and degradation) (25\%), and cell (5.6\%) (Fig. 3a). In Yousef, 7.5 percent of detected DAPs were involved in carbohydrate metabolism (\%), 6.7 percent in lipid metabolism, 8.4 percent in amino acids metabolism, 15.2 percent in misc, 3.3 percent in each of RNA and DNA, 20.3 percent in proteins metabolism (synthesis and degradation), and 5 percent in the cell wall (degradation and modification), signalling and cell. In Morocco, detected DAPs were implicated in carbohydrate metabolism (18.7\%), protein metabolism (18\%), lipid metabolism (3.7\%), amino acid metabolism (2.2\%), secondary metabolism (4.5\%), redox (3\%), stress (7.5\%), misc (7.5\%), signalling (2.2\%), RNA (10.5\%) and cell (3.7\%). In PBYT17, the largest percentage of detected DAPs were involved in carbohydrate metabolism (9.7\%), cell wall (3.2\%), lipid metabolism (3.2\%), amino acids metabolism (4.3\%), secondary metabolism ( $2 \%)$, stress (3.2\%), redox (6.5\%), nucleotide metabolism (2.1\%), misc (4.3\%), DNA (1\%), RNA (1\%), proteins metabolism (synthesis and degradation) (10.8\%), and signalling (5.4\%) (Fig. 3b).

In terms of DAPs, 420 proteins were increased and 401 proteins were decreased at 28 DAA. The highest number of DAPs was observed in PBYT17 and Morocco and the lowest in Yousef. These proteins were then categorized as: carbohydrate metabolisms (6.8\%), protein metabolism (20.45\%), signalling (6.8\%), cell wall (9\%), lipid metabolism (13.6), amino acids metabolism (6.8\%), misc (6.8\%), and RNA (6.8\%) in Yousef. In Morocco, detected DAPs were implicated in carbohydrate metabolism (8.89\%), protein metabolism (24.47\%), amino acid metabolism (4.49\%), secondary metabolism (5.6\%) and RNA (6.67\%). In PBYT17, detected proteins were implicated in carbohydrate metabolism (14.5\%), lipid metabolism (6.45\%), stress (4.82\%), protein metabolism (11.2\%), amino acid metabolism (8.06\%) and RNA (6.45\%) (Fig. 4a). Proteins involved in carbohydrate metabolisms (18.27\%), stress (4.3\%), misc (7.5\%), RNA (8.6\%), protein metabolism (30.1\%), signalling (3.2\%), lipid metabolism (3.2) were decreased in Yousef. In Morocco, detected proteins implicated in carbohydrate metabolism (5.8\%), lipid metabolism (5.8\%), stress (8.8\%), misc (14.7\%), protein metabolism (20.5\%), nucleotide metabolism (5.8\%) and RNA (8.8\%) were decreased. In PBYT17, detected DAPs were implicated in carbohydrate metabolism (8.13\%), lipid metabolism (4.06\%), stress (4.8\%), redox (3.25\%), misc (6.5\%), protein metabolism (20.3\%), transport (5.6\%), signalling (6.5\%) and RNA (10.5\%) (Fig. 4b). 
Figure 5 shows the DAPs different expression patterns in Yousef, Morocco, and PBYT17 genotypes. There were only 14 DAPs common in all three genotypes. Although the expression level of drought-responsive proteins in susceptible cultivar was higher than semi-tolerant cultivar, however, an overlap in expression levels of these proteins was observed in susceptible and semi-tolerant genotypes. A total of 52 shared proteins in both susceptible and semi-tolerant barley genotypes, were expressed. At 21 days after anthesis, 25 and 36 shared proteins between Yousef with PBYT17 and Morocco were observed, respectively (Figure 5a). At 28 days after anthesis, there were only 8 shared proteins among the three genotypes. However, the drought-responsive proteins were higher in semi-tolerant genotype than tolerant and susceptible genotypes. A total of 34 shared proteins was observed between susceptible and semi-tolerant genotypes. Also, 29 and 60 shared proteins between Yousef with PBYT17 and Morocco were observed, respectively (Fig. 5b).

\title{
Multivariate data analysis of differentially abundant proteins
}

A multivariate statistical test, partial least squares discriminant analysis (PLS-DA), was performed to detect proteins which could distinguish up to $55.7 \%$, $56.8 \%, 60.9 \%, 66.3 \%, 61.9 \%, 59.5 \%$, and of proteome variations across control and drought conditions (Fig. $6 \mathrm{~b}, \mathrm{~d}, \mathrm{f}$ and Fig. $7 \mathrm{~b}, \mathrm{~d}, \mathrm{f}$ ). To evaluate the difference in frequency of a protein between control conditions and drought conditions, the value of the predictive effect variable (VIP)> 1.0 was used. The abundance of about $41 \%, 42 \%$ and $32 \%$ proteins were permanently differentiated in Morocco, PBYT17, and Yousef at 21 DAA in response to drought stress (Fig. 6a, c, e). These mainly include proteins involved in carbohydrate metabolism, transport and amino acids metabolism in Morocco and stress, protein post-translational and secondary metabolism in Yousef, as well as, proteins involved in cell organization in PBYT17. While the abundance of about $50 \%, 41 \%$ and $42 \%$ proteins were permanently differentiated in Morocco, PBYT17, and Yousef at 28 DAA in response to drought stress. These proteins were mainly belonged to lipid metabolism, signalling, and cell wall degradation functional groups in Yousef and RNA regulation and cell organization and protein synthesis/degradation functional groups in Morocco at 28 DAA. Also, proteins involved in transport and RNA regulation in PBYT17 (Fig. 7 a, c, e).

\section{Discussion}

In this study, we used tandem mass spectrometry based proteomics technology to identify proteins modulating remobilization efficiency in three contrasting barley genotypes. Our data showed that differential expression analysis and physiological traits provide a valuable data for gaining systems-level insights into the remobilization of dry matter and response to drought stress in barley. Here the crucial roles of DAPs are discussed in details under drought stress conditions.

\section{DAPs with higher abundance in tolerant genotype}

\author{
Proteins involved in stress increased in abundance in tolerant genotype at 21 DAA
}

The abundance of several proteins related to abiotic and biotic stresses such as Wound induced protein, Chaperone clpb putative, NBS-LRR resistance like proteins, and $70 \mathrm{kDa}$ heat shock protein may play important roles at the seed filling stage (Supplementary Table S1). Our findings disagree with other results, indicating that chaperone proteins are increased in the endosperm, and the proteins involved in cell division, cell wall degradation, and growth are decreased ${ }^{9}$. Other proteins involved in stress include NBS-LRR resistance like protein (PR protein) which act in the defense and sugar remobilization in plants. PR proteins are regulated and found in leaves of healthy tobacco plants during flowering and are constitutively present in bean leaves ${ }^{21}$. A pervious study has shown that chaperones are regulated in sunflower seeds and are also regulated in response to water stress ${ }^{22}$. We suggested that molecular chaperones are responsible for protecting cells from stress damage, and their major function was determined as stabilizing protein folding. Another study has shown that wound-induced proteins are induced in response to wounding in plants, and this protein, in particular, is thought to be involved in cell wall modifications ${ }^{23}$. The Woundinduced proteins are regulated at translational and/or post-translational levels during seed development.

\section{Proteins involved in protein post-translational modification increased in abundance in the tolerant genotype at 21 DAA}

The abundant protein of most of proteins implicated in protein post-translational modification increased in response to drought stress in the tolerant genotype. The important proteins with the prominent roles included protein serine threonine phosphatase (PSP), Protein kinase superfamily protein LENGTH 495, and Metallo beta lactamase domain (Supplementary S1). The possible roles of serine-threonine protein phosphatases in plants include oxidative stress signalling. The functions of serine-threonine protein phosphatases affect the ROS-related developmental stages and PP2A inhibitors in vascular plants. Protein kinases (PKs) are messengers which phosphorylation cascades and play key parts in drought responses ${ }^{24}$. We can propose that a complex of signalling was prompted under drought conditions, which relayed messages through the plasma membrane to the cell, activating a signal transduction cascade. Consequently, TFs were controlled by the PKs, as a result affecting response to the downstream drought-responsive genes, allowing barley to regulate its growth and development under drought stress.

Several protein kinases have been showed to be involved in the plant nitrogen regulatory network ${ }^{24,25}$. Many studies have suggested that manipulation of proteins for primary and secondary nitrogen assimilatory pathways is also an favourable strategy to improve nitrogen use efficiency 25,26 . It can be speculated that in the pathway of starch biosynthesis, protein kinase activities have been regulated by phosphorylation/dephosphorylation, indicating that these proteins may function as regulatory systems in this pathway in the tolerant genotype.

Proteins involved in the secondary metabolism increased in abundance in the tolerant genotype and decreased in the susceptible and semi-tolerant genotypes at 21 DAA

The abundance of several proteins such as methyltransferase, Geranylgeranyl reductase and Isoflavone reductase were increased in response to drought stress only in the tolerant genotype (Supplementary S1). The Geranylgeranyl reductase (GGR) is a flavin-containing redox enzyme that hydrogenates a range of unactivated polyprenyl substrates, which are processed for lipid biosynthesis and tocopherol in plants. Similarly, the increase of the geranylgeranyl 
reductase (GGR) protein, which may be induced by ABA deficiency during the pre-storage phase, hydrogenate a variety of unactivated polyprenyl substrates ${ }^{27}$ Isoflavone reductase (IFR) is an enzyme implicated in the biosynthetic pathway of isoflavonoid phytoalexin in plants. IFRs are considered to have important roles in plant response to different environmental stresses and are determined as key enzyme involved in the synthesis of the glyceollins from daidzein 28,29 The methyltransferase is a great family of enzymes that methylate the oxygen atom of a variety of secondary metabolites including phenyl-propanoids, flavonoids, and alkaloids. Methylation plays an essential role in response to stress and disease resistance in plants. We may propose that the tolerant genotype uses various pathways to tolerate drought stress, one of which is the activation of enzymes involved in the biosynthesis of flavonoids.

\section{Proteins involved in lipid metabolism increased in abundance in tolerant genotype at 28 DAA}

Lipids metabolism is one of the most important metabolism in plants in response to abiotic stresses. In water stress, the increase of several proteins is essential for lipid metabolism such as Phospholipases and Non-specific lipid-transfer proteins (Supplementary S1). Non-specific lipid-transfer proteins are one of the constituents of lipid transfer proteins (LTPS), a group of cysteine-rich soluble proteins, having small molecular weights. Aside from its participation in flower and seed filling. LTPs also are essential in response to biotic and abiotic stresses ${ }^{30}$. The Non-specific lipid-transfer protein and Phospholipase D decreased in the susceptible and semi-tolerant genotypes and increased in the tolerant genotype (Supplementary Table S1). Phospholipases cleave small molecules from plasma membrane phospholipid heads which then act as second messengers. Phospholipase $D$ enzymes cleave phospholipids and generate lysolipids in signalling pathway. Increases of Phospholipase D activity in plants were observed in response to auxin and developmental processes ${ }^{31}$. Activation of PLD has been reported as signalling molecule in response to abscisic acid (ABA) induction, where plant cells close stomata and decrease transpiration water loss under water deficit condition. We may conclude that PLD activity increased with the maturity of leaves of barley, reaching maximum at the seed filling stage.

\section{Proteins involved in signalling increased in abundance in tolerant genotype at 28 DAA.}

Signalling proteins play key roles in response to drought stress, indicating their functions as messengers in remobilization in seed filing. Signalling G-proteins are important in seed germination and had interaction with sugars and $\mathrm{ABA}^{32}$. The abundant proteins of Ras related protein Rab $8 \mathrm{~A}, \mathrm{Calcium}$ binding $\mathrm{EF}$ hand family protein and Ran GTPase activating protein increased in the tolerant genotype and decreased in the susceptible and semi-tolerant genotypes (Supplementary S1). The increase of rab protein in Longchun 23 may act as regulator in membrane-trafficking pathways ${ }^{33}$. Calcium ion (Ca ${ }^{2+}$ ) is a second messenger, playing a key role in plant responses to various physiological and environmental stimuli. Although there are several $\mathrm{Ca}^{2+}$ sensing molecules found in a cell, EF-hand containing proteins play a principal role in calcium signalling event in plants. Calcium-binding proteins are proteins that are involved in the calcium signalling pathway by binding to calcium ions, playing an important role in many cellular processes ${ }^{34}$. The expression of Calcium binding EF hand family protein play a key role in drought tolerance during the seed germination and early growth stages ${ }^{35}$.

\section{Proteins involved in cell wall degradation increased in abundance in the tolerant genotype at 28 DAA}

Senescence associated proteins are in involved cell wall degradation and modification. The most abundant senescence-associated proteins are involved in glucose biosynthesis. This process is controlled by key cell wall degradation enzymes, which are a heterogeneous enzyme group. Glycoside hydrolases (cell wall degradation enzymes) play roles in different biological processes like cell wall metabolism, plant defense, signalling, starch degradation and remobilization of storage reserves (glucose). Endo 2,4 beta xylanase, Alpha $\mathrm{N}$ arabinofuranosidase $\mathrm{A}$ and Beta $\mathrm{D}$ glucosidases were increased in the tolerant genotype (Supplementary S1). Endo 2,4 beta xylanase plays important role in hydrolyzing xylan backbones into shorter, soluble xylo-oligo saccharides ${ }^{36}$. Xylanase is strongly expressed in mobilizing nutrients from the aleurone layer and endosperm to the developing seed ${ }^{37}$. Proteins involved in cell wall hydrolase in tolerant genotype play a key role in carbon remobilization in seed filing under drought stress. Genes involved in the biosynthesis of starch and sucrose, such as beta-glucosidase, catalyze the hydrolysis of starch, which changes the expression of these genes in wheat at the grain filling stage ${ }^{3}$. Beta D glucosidases are enzymes that hydrolyze cellulose resulting in the formation of glucose. The pathway of releasing glucans through the degradation of starch granules by these enzymes is not yet well defined. This pathway is dependent on plant species and physiological conditions ${ }^{38}$. It has been reported that cell wall hydrolytic enzymes are involved in many different functions, such as stem remobilization at the seed filling ${ }^{39}$. We suggest that proteins involved in cell wall hydrolase in the tolerant genotype play a key role in carbon remobilization at the seed filling and can be considered as suitable candidate proteins under drought stress.

\section{DAPs with lower abundance in tolerant genotype Proteins involved in carbohydrate metabolism increased in abundance in susceptible genotype at 21 DAA}

The conversion of starch to sucrose is necessary for carbon reserve mobilization. The highest number of proteins involved in starch cleavage, sucrose synthase, and beta-fructofuranosidase increased in the susceptible genotype at 21 DAA but was maintained in the tolerant and semi-tolerant genotypes (Supplementary S1). The hydrolysis of sucrose to glucose and fructose was facilitated using invertase (beta -fructofuranosidase) ${ }^{40}$. The activity of betafructofuranosidase was high at the early seed filling stage in sorghum ${ }^{41}$. Glycosyl transferase is one of the most important enzymes involved in starch degradation and sucrose biosynthesis. Sucrose synthase is glycosyl transferase and plays an important role in seed filling. Sucrose synthase is a glycosyl transferase enzyme, playing a pivotal role in sugar metabolism and catalyzing the reversible cleavage of sucrose into fructose. In the present study, sucrose synthase was increased in the susceptible genotype. Sucrose synthase, as one of the key enzymes in sucrose synthesis, plays a key role in regulating the sucrose content of cells ${ }^{42}$. We can conclude that the enzymes of the carbon assimilation pathway are strongly modulated during drought in the susceptible genotype. Glycolysis and TCA are important pathways in carbon and nitrogen metabolism, considered as sources of energy to carbon remobilization. 
Furthermore, the abundance of two tricarboxylic acid cycle (TCA) enzymes, succinyl-CoA ligase, and Pyruvate dehydrogenase, decreased in the tolerant and semi-tolerant genotypes. Our results indicated that glycolysis enzymes are consistent with a drought-mediated function in photosynthetic carbon metabolism. The tricarboxylic acid (TCA) cycle is essential for cellular energy metabolism and carbon skeleton supply ${ }^{43}$. It is speculated that the increase in abundance of this protein in the susceptible genotype might be the mechanism, as an energy source, for the viability and survival during drought stress.

\section{Proteins involved in amino acids metabolism increased in abundance in the susceptible genotype and decreased in the tolerant genotype at 21 DAA}

Amino acids metabolism provides sufficient energy for sugar metabolism and can regulate proteins in response to drought stress ${ }^{44}$. Amino acids have crucial roles in different metabolic processes and serve as the main precursors for various primary and secondary metabolites, including amino acids, and other metabolites during seed filling ${ }^{45}$. In the susceptible genotypes, the abundance of several proteins involved in amino acids metabolism decreased in response to drought stress (Supplementary S1). S-adenosylmethionine is a precursor for the synthesis of ethylene, biotin, and polyamines. S-adenosylmethionine synthase (SAMs) and cysteine synthase were increased in the susceptible genotype but maintained in the tolerant and semi-tolerant genotypes. SAMs play central roles in many cellular biochemical reactions and are involved in the biosynthetic pathways of ethylene and polyamines (PAs), interacting with physiological processes and stress responses. A previous survey has shown that S-adenosylmethionine synthase plays an important role in polyamine metabolism ${ }^{33}$. Based on our results, we proposed that S-adenosylmethionine synthase plays a key role in germination and polyamine and response to abiotic stresses in susceptible genotypes. Cysteine synthases are crucial enzymes in synthesizing amino acids and essential in seed development and seed filling. The cysteine synthase enzyme is in the cytosol and chloroplast and forms the center of a unique metabolic sensing and signalling system ${ }^{46}$. We suggested that cysteine synthase may have important roles in regulating carbon and nitrogen metabolism, which potentially is involved in nitrogen re-translocation during the seed filling.

\section{Proteins involved in transport increased in abundance in susceptible genotype and decreased in tolerant genotype at 21 DAA}

Plant hormones control many of plant processes, such as seed germination and reproduction as well as organ development. Phyto-hormonal transporters belonging to the ATP-Binding Cassette family (ABC proteins) can used as new candidate proteins in important species for food production ${ }^{47}$. The plants use various transporters for energy during drought stress and as well as plant growth and developments. Transporter proteins are the most important carrier for carbon and nitrogen remobilization in seed filling. V-type proton ATPase subunit d2 and ATP-Binding Cassette family (ABC proteins) were decreased in the tolerant and semi-tolerant genotypes and increased in the susceptible genotype. V-type proton ATPase has ATPase function and participates in the formation of a proton channel that is responsible for proton transport (Supplementary S1). A previous study has shown that V-type proton ATPase subunit increased in mature seeds, cotyledons, leaves, stems, roots, and anthers ${ }^{48}$. Transporters act as a proton pump, facilitating energy for ion transport that allows growth and survival in drought stress conditions in the susceptible genotype.

\section{Proteins involved in protein synthesis/ degradation increased in abundance in susceptible genotype at 28 DAA}

Protein biosynthesis is absolute requirement for plant growth which is done through ribosomal proteins. Ribosome biogenesis is directly expressed by the environmental stresses, nutrient availability for stem remobilization through transporters during seed filling. The highest number of proteins involved in protein synthesis/degradation were increased in the susceptible genotype (Supplementary S1). Many ribosomal proteins represent not only the protein components but also precursors of various stress-related compounds and key components of metabolic pathways related to carbon and nitrogen metabolism in stem remobilization ${ }^{49,50}$. Many proteins are subjected to ubiquitin proteasome-dependent degradation. Also, protein degradation pathways include essentially proteins associated with protein targeting by ubiquitin to proteasome degradation. Ubiquitin conjugating enzyme E2 increased in tolerant and susceptible genotypes. A pervious study has shown that ubiquitin-conjugating enzyme gene $E 2$ increased expression stability in the developing pea seed ${ }^{51}$. Another study showed that the accumulation of proteins mainly related to protein synthesis, folding, and degradation maintains the protein pools for regulation and maintenance of cell function and adapt to environmental challenges ${ }^{52}$. The high number of proteins involved in the biosynthesis/degradation of proteins in the susceptible genotype, as compared with the tolerant genotype, may have positive impact on survival and viability under drought stress.

\section{Proteins involved in RNA increased in abundance in susceptible genotype at 28 DAA}

Transcription factors (TFs) may play vital roles in various biological processes. TFs interact with other molecules and are implicated in energy transfer and take part in signalling pathways. In this study, Zinc finger protein 7 and bZIP proteins were increased in the susceptible genotype (Supplementary S1). bZIP factors have been detected during the seed filling phase such as ABI5 (ABSCISIC ACID INSUSCEPTIBLE 5) and EEL (ENHANCED EM LEVEL). Two bZIPS, AtbZIP10 and AtbZIP25, were identified during seed filling in Arabidopsis but were induced in vegetative tissues ${ }^{53}$. The Zinc finger and bZIP, regulated in starch biosynthesis, have been also detected in several species such as maize, barley, sweet potato, and Arabidopsis ${ }^{53,54}$. We may propose that TFs have unique responses to drought stress in the susceptible and tolerant genotypes, indicating differences in hormone-dependent regulation pathways. The presence and activity of TFs is modulated by several phytohormones and are up-regulated during the alarm phase of stress such as ABA. Proteins such as zinc finger proteins regulate stress signals in rice ${ }^{55}$. Similarly, zinc finger proteins showed stress-responsive expression in Brassica under salt and drought stresses ${ }^{56}$. We may speculate that TFs may play a potential role in plant growth and development in the susceptible barley genotype during drought stress.

Proteins involved in cell organization increased in abundance in susceptible genotype at 28 DAA. Several differentially abundant proteins in the susceptible genotype are related to fibrillins (Plastid lipid associated protein PAP fibrillin family protein) and Annexin (Supplementary S1). Fibrillins are lipid-binding proteins of plastids that are expressed during abiotic stress conditions. Fibrillin expression is regulated in response to ABA stress ${ }^{57}$. Annexins are able to bind $\mathrm{Ca} 2+$, oxidation and reduction signals, and lipids to respond to biotic and abiotic stresses. The expression and abundance of plant Annexins are probably related to growth and cell cycle. ${ }^{58}$. We concluded that fibrillin and Annexins accumulation contribute to the protection of the susceptible genotype in response to drought stress. 


\section{Conclusion}

A comparative analysis between different genotypes was performed to identify molecular mechanisms of enhanced stem reserves remobilization in barley in response to stress. Our results provided evidence that drought stress enhanced the stem senescence and reserve remobilization, to a greater extent in tolerant genotype. Our propose model showed the changes in the abundance of proteins in drought tolerant and drought susceptible barley genotypes under drought stress (Fig. 8). Tolerant genotype increased the abundance of a number of cell wall degradation like Endo 1,4 beta xylanase, Beta D glucosidases and Alpha $\mathrm{N}$ arabinofuranosidase A, along with a posttranslational-associated protein such as protein kinase and protein serine threonine phosphatase (PSP) involved in carbon remobilization and decreased transcription factors in response to drought stress. These proteins might play a significant role in the remobilization process of seed barley development by saving energy during seed filling stage. However, in the susceptible genotype the abundance of transcription factors increased to provide energy sources for the growth and survival during drought stress. These findings can help to develop strategies to improve drought tolerance in barley and to gain comprehensive knowledge of the basic molecular mechanisms involved in drought response.

\section{Declarations}

\section{Acknowledgements:}

This research was supported by a grant awarded by Agriculture Biotechnology Research Institute of Iran, (ABRII) and Shahid Beheshti Univesity. We would like to appreciate Dr. Adnan Al-Yassin, (ICARDA) who kindly provided the Morocco 9-75 seeds. Moreover, the authors are grateful to Dr. HamidReza Nikkhah (SPII) for providing seeds of the spring barley cv Yousef and PBYT27 line.

\section{Contributions}

M.R.G., A.S., and G.H.S designed this work. Z.H. performed the experiments. Z.H., M.Z., M.M., A.M.G. and M.S. carried out data proteome and data analysis. All authors discussed the results. Z.H. and M.R.G. wrote the manuscript. M.R.G. and A.S. edited the final version of the manuscript. Correspondence should be addressed to A.S. and M.R.G.

\section{Competing interests}

The authors declare no competing interests

\section{References}

1. González, A., Martín, I. \& Eyerbe, L. Yield and osmotic adjustment capacity of barley under terminal water-stress conditions. J Agron Crop Sci.194, 81-91 (2008).

2. Bannayan, M., Sanjani, S., Alizadeh, A., Lotfabadi, S. S. \& Mohamadian, A. Association between climate indices, aridity index, and rainfed crop yield in northeast of Iran. Field Crops Res.118, 105-114 (2010).

3. Ehdaie, B., Alloush, G.A., Madore, M.A. \& Waines, J.G. Genotypic variation for stem reserves and mobilization in wheat: I. Postanthesis changes in internode dry matter. Crop Sci. 46,735-746 (2006).

4. FAO. Crop Prospects and Food Situation - Quarterly Global Report No.1. https://doi.org/10.4060/ca8032en (2020).

5. Francia, E. et al. Two loci on chromosome $5 \mathrm{H}$ determine low-temperature tolerance in a 'Nure'(winter)×'Tremois'(spring) barley map. Theor. Appl. Genet.108,670-680 (2004).

6. Afshari-Behbahanizadeh, S. et al. Qualitative and Physical Properties of Barley Grain s under Terminal Drought Stress Conditions. J. Agric. Sci. Technol. 18, 1303-1317 (2018).

7. Ehdaie, B., Alloush, G. A. \& Waines, J. G. Genotypic variation in linear rate of grain growth and contribution of stem reserves to grain yield in wheat. Field Crops Res.106, 34-43 (2008).

8. Joudi, M., Ahmadi, A., Mohamadi, V., Abbasi, A., Vergauwen, R., Mohammadi, H. \&Van den Ende, W. Comparison of fructan dynamics in two wheat cultivars with different capacities of accumulation and remobilization under drought stress. Physiol. Plant.144, 1-12 (2012).

9. Ma, J., Huang, G. B. Yang, D. L. \& Chai, Q. Dry matter remobilization and compensatory effects in various internodes of spring wheat under water stress. Crop Science.54, 331-339 (2014).

10. Khoshro, H .H., Taleei, A. Bihamta, M. R. Shahbazi, M. Abbasi, A. \& Ramezanpour, S. S. Expression analysis of the genes involved in accumulation and remobilization of assimilates in wheat stem under terminal drought stress. Plant Growth Regul. 74,165-176 (2014).

11. Bahraei, S., Saidi, A. \& Alizadeh, D. High molecular weight glutenin subunits of current bread wheats grown in Iran. Euphytica, 137, 173-179 (2004).

12. Abouzar, M., Shahbazi, M., Torabi, S., Nikkhah, H. R. \& Nadafi, S. Post-anthesis changes in internodes dry matter, stem mobilization and their relation to the grain Yield of Barley (Hordeum vulgare L.). Iran. J. Plant Physiol. 2, 553-557 (2012). 
13. Hübner, S., Korol, A.B. \& Schmid, KJ. RNA-Seq analysis identifies genes associated with differential reproductive success under drought-stress in accessions of wild barley Hordeum spontaneum. BMC Plant Biol. 15, 1-4 (2015).

14. Goggin, D.E. \& Setter, T. L. Fructosyltransferase activity and fructan accumulation during development in wheat exposed to terminal drought. Funct. Plant Biol. 31, 11-21 (2004).

15. Yang, J., Zhang, J., Wang, Z., Zhu, Q.\& Liu, L. Activities of fructan and sucrose-metabolizing enzymes in wheat stems subjected to water stress during grain filling. Planta. 220, $331-343$ (2004).

16. Kerepesi, I. \& Galiba, G. Osmotic and salt stress-induced alteration in soluble carbohydrate content in wheat seedlings. Crop Sci. 40,482-487 (2000).

17. Amiour, N., Merlino, M., Leroy, P. \& Branlard, G. Proteomic analysis of amphiphilic proteins of hexaploid wheat kernels. Proteomics. 2, 632-641 ( 2002).

18. Bazargani, M.M. et al. A proteomics view on the role of drought-induced senescence and oxidative stress defense in enhanced stem reserves remobilization in wheat. J Proteomics. 74,1959-1973 (2011).

19. Li, Z. et al. Proteomic analysis of positive influence of alternate wetting and moderate soil drying on the process of rice grain filling. Plant Growth Regul. 84, 533-548 (2018).

20. Wang, G. et al. Regulation of gene expression involved in the remobilization of rice straw carbon reserves results from moderate soil drying during grain filling. Plant J. 101,604-618 (2020).

21. Tuzun, S. The relationship between pathogen induced systemic resistance and multigenic resistance in plants. Eur J Plant Pathol. 107, 85-93 (2001).

22. Alamillo J, Almogura C, Bartels D, Jordano J. Constitutive expression of small heat shock proteins in vegetative tissues of the resurrection plant Craterostigma plantagineum.Plant Mol Biol.29, 1093-1099 (1995).

23. Savatin DV, Gramegna G, Modesti V, Cervone F. Wounding in the plant tissue: the defense of a dangerous passage. Front. Plant Sci.5, 470 (2014).

24. Liu S, Zenda T, Dong A, Yang Y, Wang N, Duan H. Global Transcriptome and Weighted Gene Co-expression Network Analyses of Growth-Stage-Specific Drought Stress Responses in Maize. Front. genet.12, 645443 (2021).

25. Yang, L., Hu, H., Zhu, B., Jin, X., Wu, F. \& Zhang, G. P. Genotypic variations of nitrogen use efficiency in Tibetan wild and cultivated barleys. J. Zhejiang Univ.40, 155-164 (2014).

26. Pathak, R. R., Ahmad, A., Lochab, S. \& Raghuram, N. Molecular physiology of plant nitrogen use efficiency and biotechnological options for its enhancement. Curr. Sci.94, 1394-1403 (2008).

27. Pathak, R. R., Lochab, S. \& Raghuram, N. “Plant systems: Improving plant nitrogen-use efficiency," in Comprehensive Biotechnology.Ed. Moo-Young, M. (Pergamon: Elsevier), 209-218. (2011).

28. Meadows, C.W. et al. Discovery of novel geranylgeranyl reductases and characterization of their substrate promiscuity. Biotechnol. Biofuels. 11,1-7 (2018).

29. Oliver, Y., Shi J., Hession A. O., Maxwell C. A., Mc Gongigle B. \& Odell J. T. Metabolic engineering to increase isoflavone biosynthesis in soybean seed. Phytochemistry.63, 753-763 (2003).

30. Cooper J. D., Qiu F. \& Paiva N. L. Biotransformation of an exogenously supplied isoflavonoid by transgenic tobacco cells expressing alfalfa isoflavone reductase. Plant Cell Rep. 20, 876-884 (2002).

31. Pan, Y., Li, J. Jiao, L. Li, C. Zhu, D. \& Yu, J. A non-specific Setaria italica lipid transfer protein gene plays a critical role under abiotic stress. Front. Plant Sci. 7, 1752 (2016).

32. Rietz, S. et al. Roles of Arabidopsis patatin-related phospholipases a in root development are related to auxin responses and phosphate deficiency. Mol Plant. 3,524-538 (2010).

33. Chen, Y., Zou, T. \& McCormick, S. S-adenosylmethionine synthetase 3 is important for pollen tube growth. Plant Physiol. 172,244-253(2016).

34. Agarwal, P., Reddy, M.K., Sopory, S. K. \& Agarwal, P.K. Plant rabs: characterization, functional diversity, and role in stress tolerance. Plant Mol. Biol. Rep.27, 417-430 (2009).

35. Chen, C. et al. GsCML27, a gene encoding a calcium-binding EF-hand protein from Glycine soja, plays differential roles in plant responses to bicarbonate, salt and osmotic stresses. PLoS One. 10 (2015).

36. Pollet, A., Delcour, J.A. \& Courtin, C.M. Structural determinants of the substrate specificities of xylanases from different glycoside hydrolase families. Crit Rev Biotechnol.30,176-191 (2010). 
37. Caspers M. P. M., Lok, F., Sinjorgo, K. M. C., Van Zeijl, M. J., Nielsen, K. A. \& Cameron-Mills V. Synthesis, processing and export of cytoplasmic endo- $\beta-1,4-$ xylanase from barley aleurone during germination. Plant J.26, 191-204 (2001).

38. Smith, A.M., Zeeman, S.C. \& Smith, S.M. Starch degradation. Annu Rev Plant Biol.56, 73-98. (2005).

39. Minic Z. Physiological roles of plant glycoside hydrolases. Planta. 227,723-40 (2008).

40. Jain, M., Chourey, P.S., Li, QB. \& Pring, D.R. Expression of cell wall invertase and several other genes of sugar metabolism in relation to seed development in sorghum (Sorghum bicolor). J. Plant Physiol.165,331-44 (2008).

41. Hirose, T., Takano, M. \& Terao, T. Cell wall invertase in developing rice caryopsis: molecular cloning of OsCIN1 and analysis of its expression in relation to its role in grain filling. Plant Cell Physiol. 43, 452-459 (2002).

42. Stein, O. \& Granot D. An overview of sucrose synthases in plants. Front. Plant Sci. 10, 95 (2019).

43. Schwer, B., Bunkenborg, J., Verdin, R., Andersen, J. \& Verdin, E. Reversible lysine acetylation controls the activity of the mitochondrial enzyme acetyl-CoA synthetase. Proc. Natl. Acad. Sci. U.S.A.103, 10224-10229 (2006).

44. Ghaffari, M. et al. Root endophytic fungus Piriformospora indica improves drought stress adaptation in barley by metabolic and proteomic reprogramming. Environ. Exp. Bot .157,197-210 (2019).

45. Min, C.W. et al. In-Depth Investigation of low-abundance proteins in matured and filling stages seeds of glycine max employing a combination of protamine sulfate precipitation and TMT-Based quantitative proteomic analysis. Cells. 9, 1517 (2020).

46. Hell, R., \& Wirtz, M. Molecular biology, biochemistry and cellular physiology of cysteine metabolism in Arabidopsis thaliana. The Arabidopsis book/American Society of Plant Biologists. 9. (2011).

47. 47. Borghi, L., Kang, J. \& de Brito Francisco, R. Filling the gap: functional clustering of ABC proteins for the investigation of hormonal transport in planta. Plant Sci. 10, 422 (2019).

48. Yang, G. et al. Overexpression of ThVHAc1 and its potential upstream regulator, ThWRKY7, improved plant tolerance of Cadmium stress. Sci Reports. 6, 17 (2016).

49. Ghabooli, M. et al. Proteomics study reveals the molecular mechanisms underlying water stress tolerance induced by Piriformospora indicain barley. $J$. Proteomics 94, 289-301 (2013).

50. Gomez, R.E. How Lipids Contribute to Autophagosome Biogenesis, a Critical Process in Plant Responses to Stresses. Cells. 10, 1272 (2021).

51. Meitzel, T. et al. Trehalose 6-phosphate promotes seed filling by activating auxin biosynthesis. New Phytol. 229, 1553-1565 (2020).

52. Zhu, J. \& Thompson, C.B. Metabolic regulation of cell growth and proliferation. Nat. Rev. Mol. Cell Biol.20, $436-450$ (2019).

53. Lara, P. et al. Synergistic activation of seed storage protein gene expression in Arabidopsis by ABI3 and two bZIPs related to OPAQUE2. J. Biol. Chem. 278, 21003-21011 (2003).

54. Zhang, X. et al. Transcriptome Analysis of Two Near-Isogenic Lines with Different NUE under Normal Nitrogen Conditions in Wheat. Biology. 10, 787 (2021).

55. Dansana, P.K., Kothari, K.S., Vij, S. \& Tyagi, A.K. OsiSAP1 overexpression improves water-deficit stress tolerance in transgenic rice by affecting expression of endogenous stress-related genes. Plant Cell Rep.33, 1425-1440 (2014).

56. Pi, B., He, X., Ruan, Y., Jang, J.C. \& Huang, Y. Genome-wide analysis and stress-responsive expression of CCCH zinc finger family genes in Brassica rapa. BMC Plant Biol. 18,373 (2018).

57. Yang, J., \& Zhang, J. Grain filling of cereals under soil drying. New Phytol.169, 223-236 (2006).

58. Blank, H.M. et al. Abundances of transcripts, proteins, and metabolites in the cell cycle of budding yeast reveal coordinate control of lipid metabolism. Mol. Biol. Cell. 31, 1069-1084 (2020).

59. Karami, A. et al. Expression analysis of dehydrin multigene family across tolerant and susceptible barley (Hordeum vulgare L.) genotypes in response to terminal drought stress. Acta Physiol. Plant. 35, 2289-2297 (2013).

60. Nikkhah, A., Ehsanbakhsh, F., Zahmatkesh, D. \& Amanlou, H. Prepartal wheat grain feeding improves energy and calcium status of periparturient Holstein heifers. Animal.5,522-527 (2010).

61. Ceccarelli, S., Grando, S. \& Baum, M. Participatory plant breeding in water-limited environments. Exp. Agric. 43,411-435 (2007). 
62. Dhanda, S. S. \& Sethi, G. S. Inheritance of excised-leaf water loss and relative water content in bread wheat (Triticum aestivum). Euphytica. 104, 39-47 (1998).

63. Salekdeh, G.H., Siopongco, J., Wade, L.J., Ghareyazie, B. \& Bennett, J. Proteomic analysis of rice leaves during drought stress and recovery. Proteomics.2, 1131-1145 (2002).

64. Mirzaei, A., Leonardi, S.G. \& Neri, G. Detection of hazardous volatile organic compounds (VOCs) by metal oxide nanostructures-based gas sensors: A review. Ceram. Int. 42, 15119-15141 (2016).

65. Fathi, A. et al. Comparative proteome and transcriptome analyses of embryonic stem cells during embryoid body-based differentiation. Proteomics.9, 4859-4870 (2009).

66. Mirzaei, M. et al. Manipulating root water supply elicits major shifts in the shoot proteome. J. Proteome Res.13, 517-26 (2014).

67. Mousavi, S.A. et al. PlantPReS: A database for plant proteome response to stress. J Proteomics.143, 69-72 (2016).

68. Thimm, O. et al. MAPMAN: A user-driven tool to display genomics data sets onto diagrams of metabolic pathways and other biological processes. Plant J. 37,914 (2004).

69. Chong, J., Yamamoto, M. \& Xia, J. MetaboAnalystR 2.0: from raw spectra to biological insights. Metabolites. 9, 57 (2019).

\section{Tables}

Table 1. levels of maximum specific weight, remobilization efficiency and remobilization rate of stem internodes in three barley genotypes under well-watered (WW) and water stress (WS) conditions.

\begin{tabular}{|c|c|c|c|c|c|c|c|c|c|c|c|c|c|c|c|c|}
\hline \multirow[t]{3}{*}{ Genotype } & \multicolumn{6}{|c|}{ Maximum specific weight $\left(\mathrm{mgcm}^{-1}\right)$} & \multicolumn{6}{|c|}{ Remobilization efficiency (\%) } & \multicolumn{4}{|c|}{ Remobilization rate (mg } \\
\hline & \multicolumn{2}{|c|}{ Peduncle } & \multicolumn{2}{|c|}{ Penultimate } & \multicolumn{2}{|c|}{$\begin{array}{l}\text { Lower } \\
\text { internodes }\end{array}$} & \multicolumn{2}{|l|}{ Peduncle } & \multicolumn{2}{|c|}{ Penultimate } & \multicolumn{2}{|c|}{ Lower internodes } & \multicolumn{2}{|c|}{ Peduncle } & \multicolumn{2}{|c|}{ Penultimat } \\
\hline & WW & NS & WW & WS & & & WW & WS & WW & & WW & & WW & WS & WW & WS \\
\hline & & & & & & & & & & & & & & & & \\
\hline Yousef & $14 \mathrm{bc}$ & $17 a$ & $22 b$ & $27 a$ & $27 a$ & $26 a$ & $35.59 b$ & $46.84 a$ & $44.91 b$ & $64.59 a$ & $36.51 b$ & $42.98 \mathrm{a}$ & $130 \mathrm{~b}$ & $160 a$ & $170 b$ & 26 \\
\hline Morocco & $7 e$ & $6.9 \mathrm{e}$ & $8.3 \mathrm{~g}$ & $g$ & $11 \mathrm{c}$ & $10 c$ & $3 \mathrm{c}$ & $d$ & 22 & 2 & 24 & 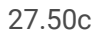 & $25 e$ & $27 e$ & $26 \mathrm{e}$ & 26 \\
\hline PBYT 17 & $13 \mathrm{~cd}$ & $13 \mathrm{~cd}$ & $21 \mathrm{bc}$ & $20.6 \mathrm{~cd}$ & $23 b$ & $23 b$ & $24.78 \mathrm{~cd}$ & $22.1 \mathrm{cde}$ & $36.61 c$ & $42.19 \mathrm{bc}$ & $43.01 a$ & $42.37 a$ & $53 c d$ & $59 c$ & $97 d$ & 12 \\
\hline
\end{tabular}

Means in each column followed by a similar letter (s) are not significantly different at $\mathrm{P}<0.05$, using Duncan Multiple Range Test

\section{Figures}


$\mathbf{2}$
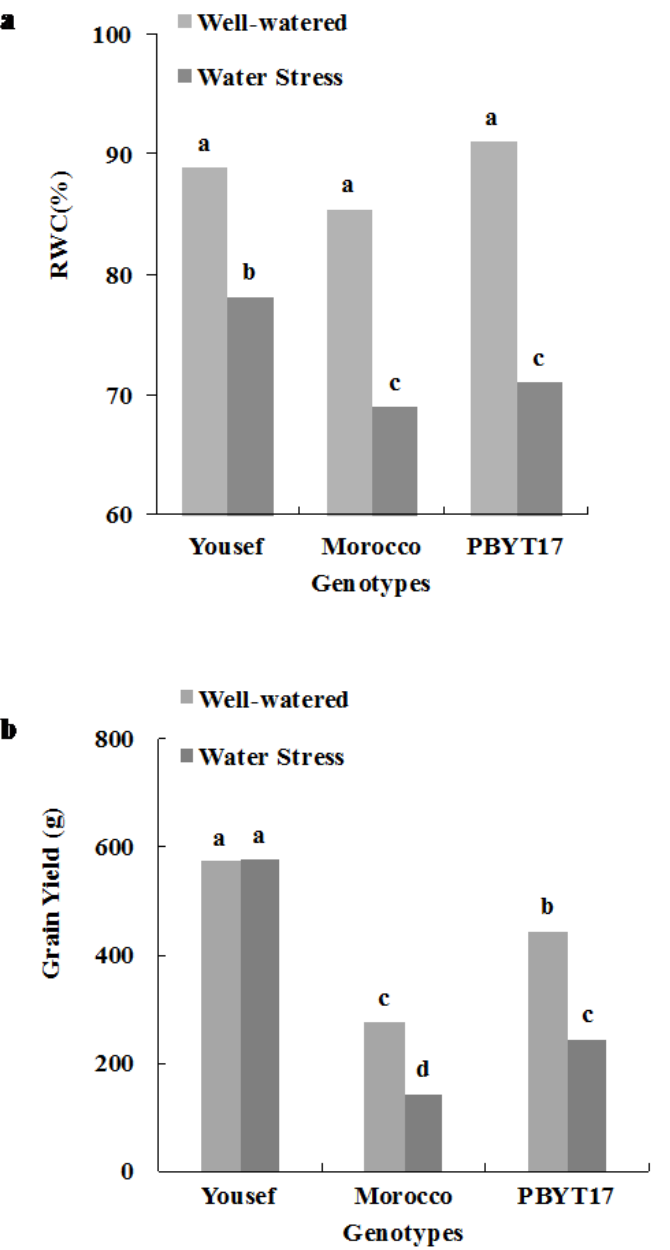

Figure 1

Relative water content (a), grain yield (b) and mean of remobilization efficiency for penultimate of flag leaves at 28 DAA in Yousef, Morocco and PBYT 17 genotypes under well- watered and water stress conditions. 


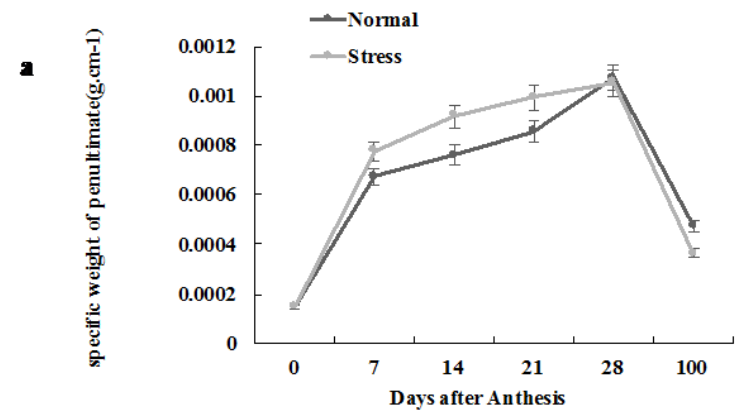

b

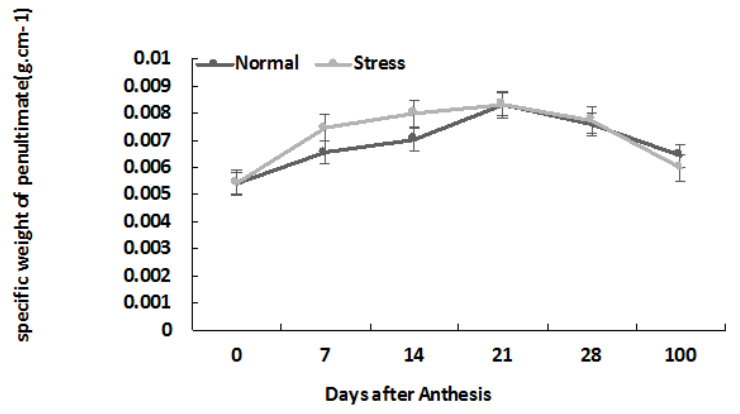

c

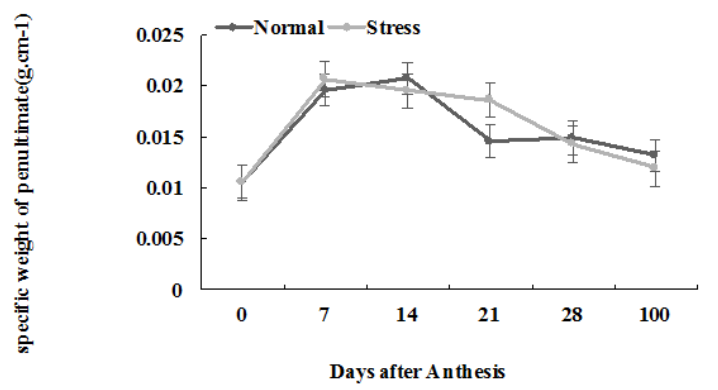

\section{Figure 2}

The specific weight of penultimate internodes in Yousef (a), Morocco (b), and PBYT17 (C) under well-watered and water stress conditions. 

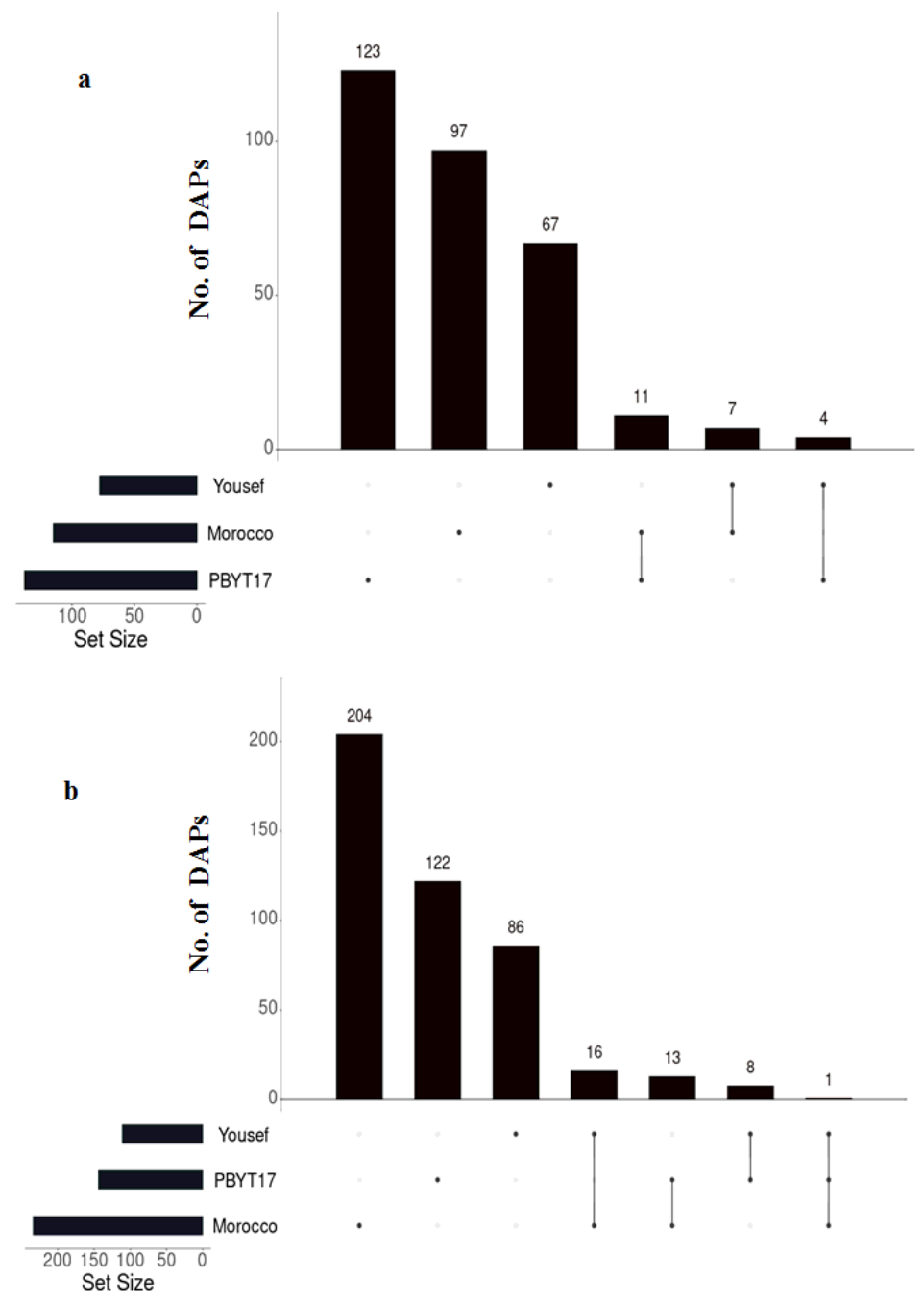

Figure 3

The Upset diagram of statistical results of up-regulated (a) and down-regulated (b) DAPs at 21 DAA in contrasting barley genotypes of Yousef, Morocco, and PBYT17. 
a

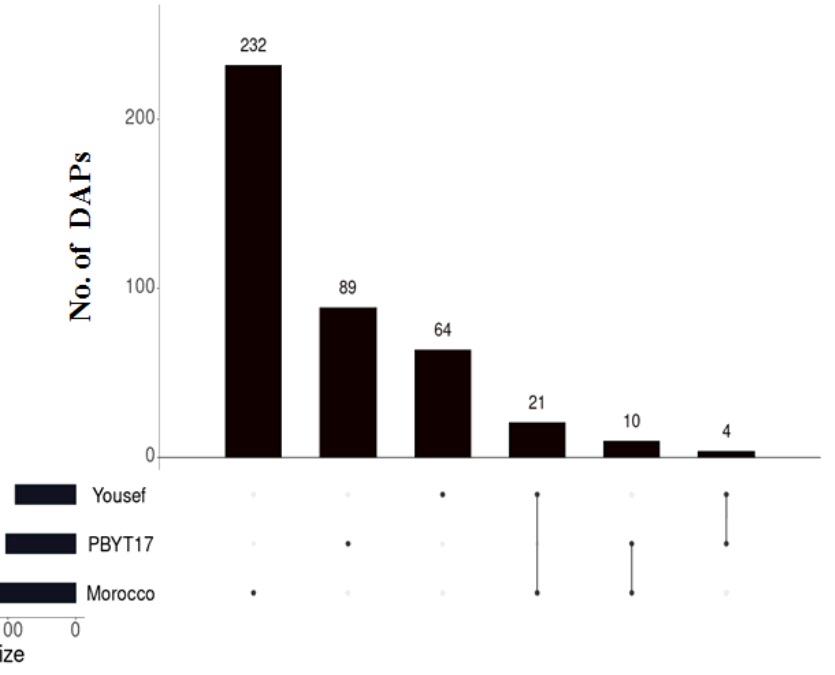

b

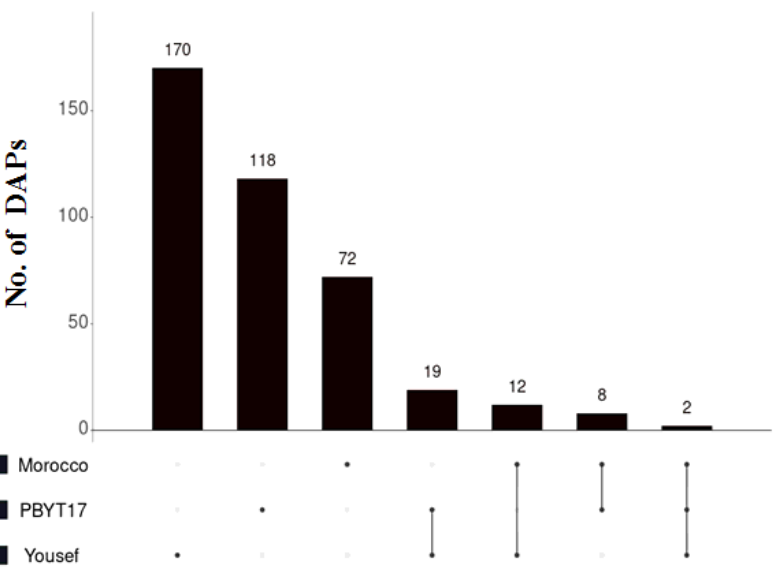

20015010050
Set Size

\section{Figure 4}

The Upset diagram of statistical results the DAPs included up-regulated (a) and (b) down-regulated at 28 DAA in contrasting barley genotypes of Yousef, Morocco, and PBYT17. 

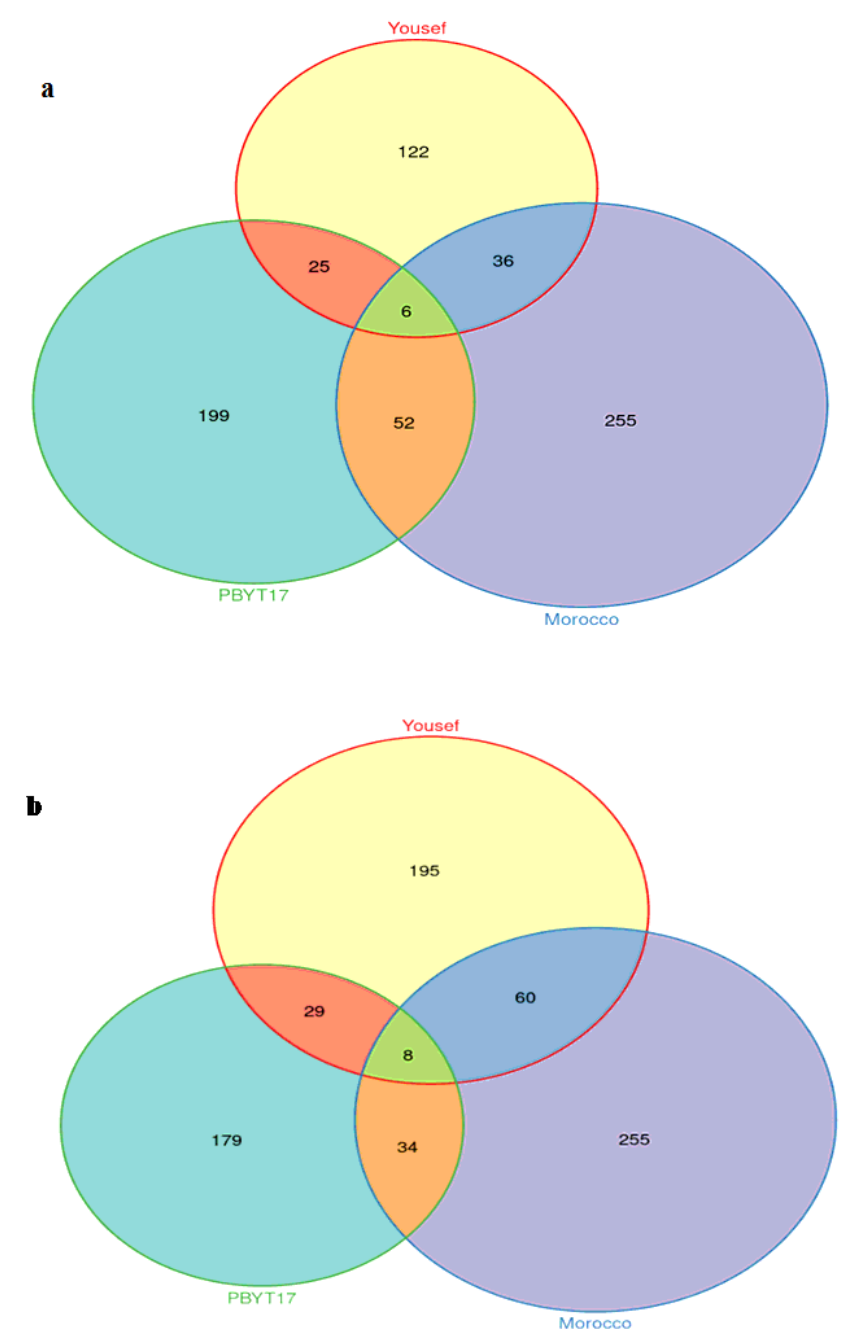

\section{Figure 5}

Venn diagram illustrates the expression patterns of drought stress-responsive proteins in penultimate internode of the barley genotypes at 21 DAA (a) and 28 DAA (b) and respectively. 
$\mathbf{a}$

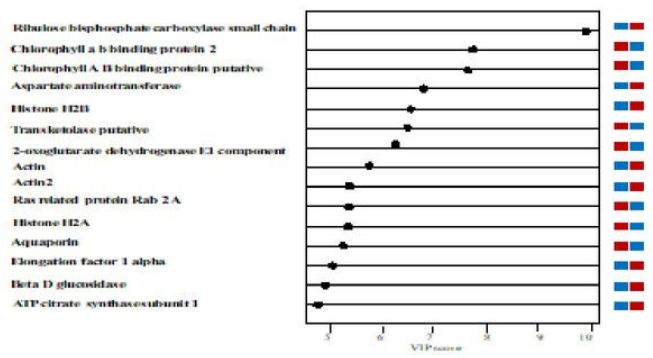

Chlarcaphsst1 a th Banding protedn 2

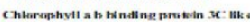
Sucromes snthase:

Caattumer sutbunit ganame

Mis ribseramal pratein $\$ 1$

NAD dequendant ephimerane daty dratan.

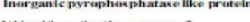

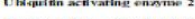
Chasta mar beta subunit putatitive rthosemat prokin

ADF rthershathen fasctor

C'crin

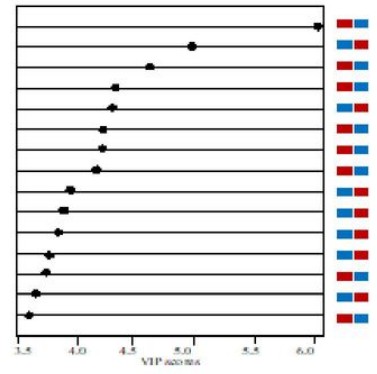

e

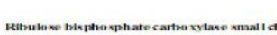

Charaphsul a b bs netin g protetein 2

Charrophst a a binating protein 2

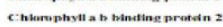

Aspartate amatheatrantiorace

The phene tow rate kinim

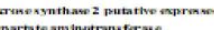

Intrane 112

Surreses aynthase

Actin 2

S atcenesed methlunine snuthase

Leacine tRN Allease

7o kb atheat shack protetein b

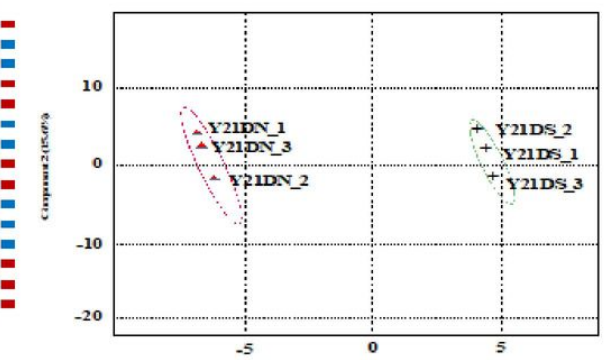

d Component 1 (40.1\%)

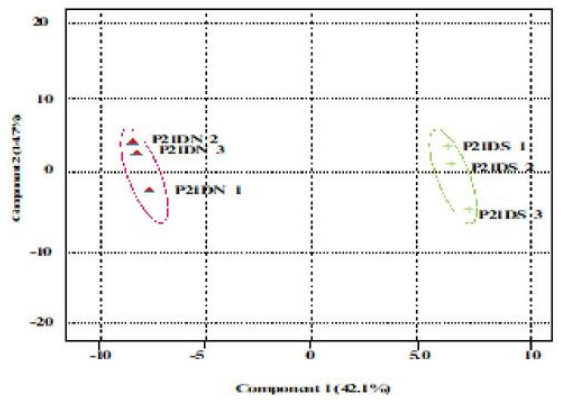

$\mathbf{f}$

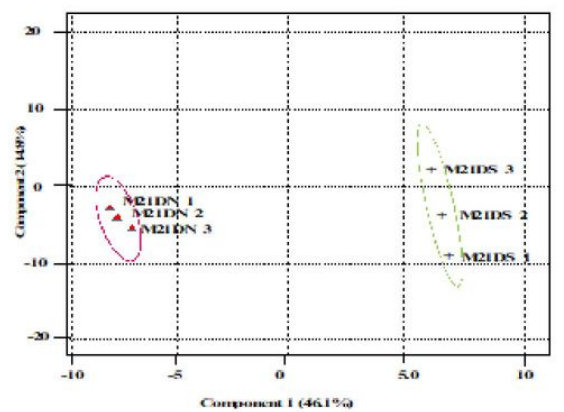

Figure 6

Multivariate statistical analysis of proteomics data from barley. Partial Least Square Discriminant Analysis (PLS-DA) score plots are presented. Control samples (well-watered after 21 days) groups are in red; drought-stressed sample groups are in green (b, $d$, f). Variable importance in projections (VIP) scores of top proteins was identified by PLS-DA obtained through MetaboAnalyst web-based platform (a, c,e). Colored boxes indicate the relative abundance of the corresponding proteins in each group under current study. Red and blue colours describe up and down-regulation of proteins, respectively. 
Chlarrophtsul a b hanating protedn 2 a b handingereatin. K: Illke

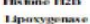

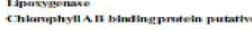
thaquitan

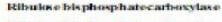
10 17monter

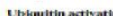

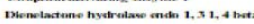
Chapernme protatun hipxi fandly protein Caatanersuturuit sanam
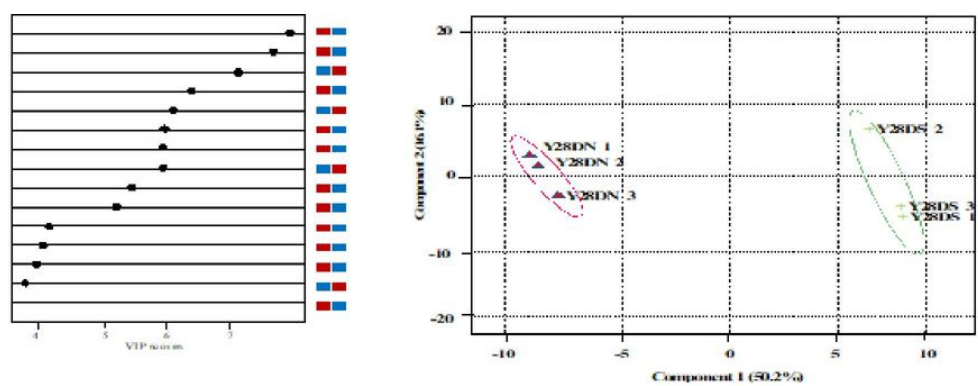

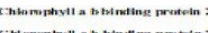

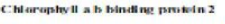

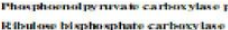

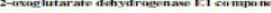
Ubifpititin patative

IIlotane 112

rmikacume suburit alpha type Champerane proutein hipici familty preatel L. nash |acsl carrier preatedn| reatuct atin 2

Ciernin lake pratein n 3a

Mnoq

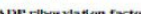
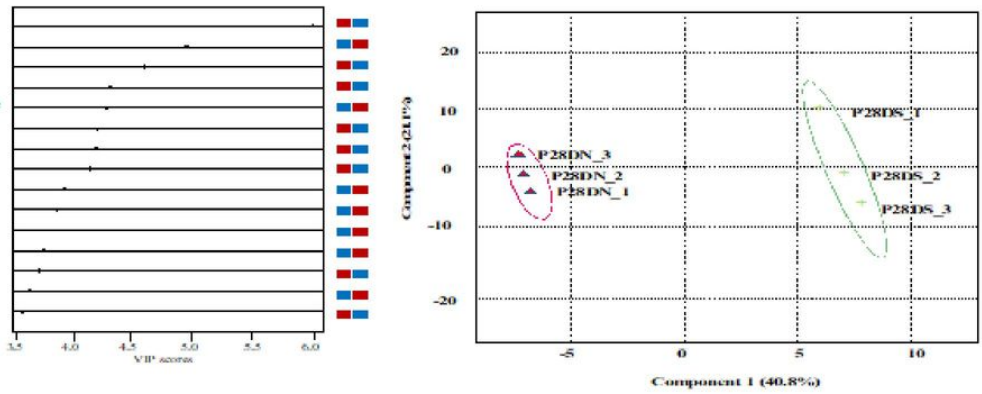

Hetbuhases Hesphesphate car

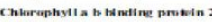

70 kDa heat thack porstetr

Chluraphyll a bbinatine protetn :

Bangation facter

Illatene $11 \mathrm{~s}$

70 kB a heat thack protedn

Leacine thN A Hean

Lipo vosenas.

Protetin of umknawn function

(1)

Protein af unkmawn fumctian
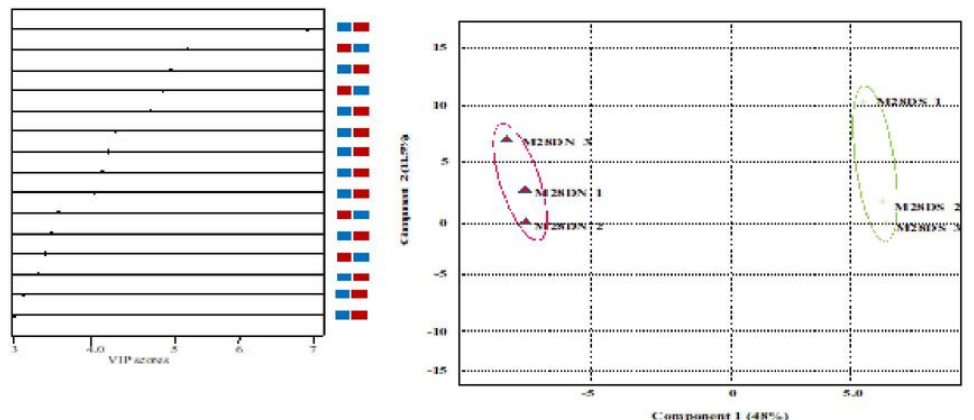

Figure 7

Multivariate statistical analysis of proteomics data from barley. Partial Least Square Discriminant Analysis (PLS-DA) score plots are presented. Control samples (well-watered after 28 days) groups are in red; drought-stressed sample groups are in green (b, d, f). Variable importance in projections (VIP) scores of top proteins was identified by PLS-DA obtained through MetaboAnalyst web-based platform (a, c, e). Colored boxes indicate the relative abundance of the corresponding proteins in each group under current study. Red and blue colours describe up and down-regulation of proteins, respectively. 


\section{$\longrightarrow$ Downrteşulated \\ $\longrightarrow$ upregegulted}

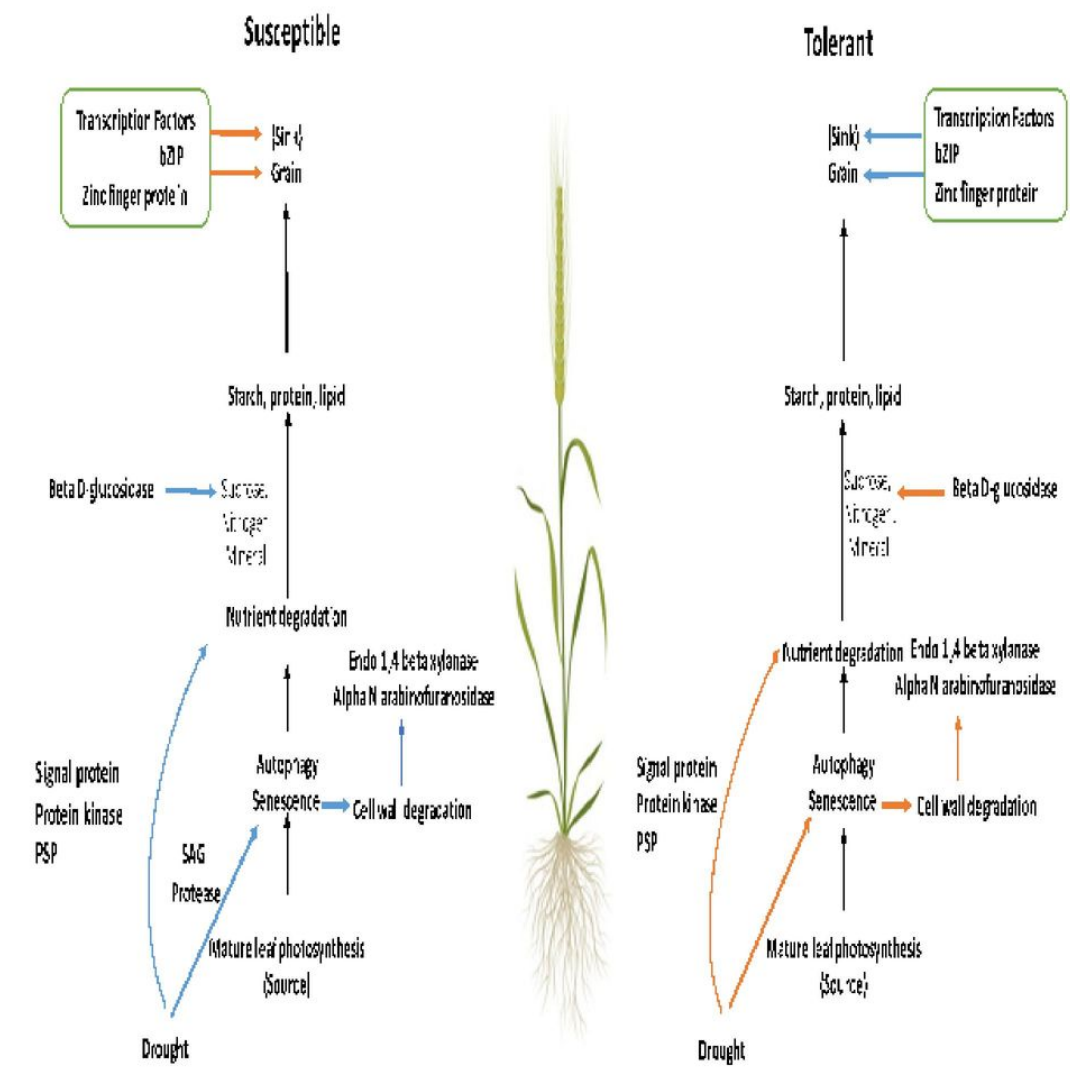

\section{Figure 8}

A model for the roles of the differentially abundant proteins linked to drought tolerance in barley. Red and blue colors show up- and down regulations respectively. Abbreviations are as follows: SAG: Senescence-Associated Genes. Protein serine threonine phosphatase (PSP).

\section{Supplementary Files}

This is a list of supplementary files associated with this preprint. Click to download.

- supplementaryS1.xIsx 